\title{
Igualdade, desigualdade e diferenças: o que é uma escola justa?
}

Flávia Schilling

\section{Resumo}

Neste artigo apresentamos os resultados de uma pesquisa que teve por título Direitos humanos, justiça e violência: percepções sobre a escola justa. 0 ponto de partida foi a constatação do impasse e da circularidade do debate sobre a violência, a reprodução das desigualdades e o desrespeito às diferenças no cotidiano escolar. Como enfrentar de forma mais oblíqua os conflitos que aí acontecem, lidando de outra maneira com as demandas por uma escola mais justa e pensando em práticas que nos podem permitir ocupar outro lugar? Na pesquisa, realizamos uma sistematização do debate teórico sobre justiça/injustiça e um estado da arte acerca do debate acadêmico sobre a questão, ambos com foco sobre as produções que cercam a escola, além de dois estudos empíricos. Neste texto, que é necessariamente um recorte de uma pesquisa mais ampla, apresentamos os resultados das percepções sobre o justo/injusto coletadas entre alunas(os) do curso de pedagogia da Universidade de São Paulo e estudantes do ensino médio, professores e gestores de uma escola pública de São Paulo. Tais resultados foram obtidos a partir da análise das respostas a uma questão que implicava um relato de uma situação justa ou injusta no mundo e de uma situação justa ou injusta na escola. Encontramos uma forte ênfase na percepção sobre a injustiça, tanto nos relatos sobre o mundo, quanto naqueles sobre a escola, comprovando a discussão teórica de que o positivo é a percepção da injustiça. Essas percepções são apresentadas a partir de algumas categorias construídas, e o artigo se encerra com uma breve exposição das propostas sobre o que seria uma escola justa.

\section{Palavras-chave}

Justiça - Direitos humanos - Violência - Escola - Igualdade Diferença.

I- Universidade de São Paulo, São Paulo, SP, Brasil. Contato: oak1@uol.com.br 


\title{
Equality, inequality and differences: what is a fair school?
}

Flávia Schilling'

\begin{abstract}
We present in this article the results of a research entitled Human rights, justice and violence: perceptions about the fair school (Direitos humanos, justiça e violência: percepções sobre a escola justa). The point of departure for the study was the observation of the impasse and circularity of the debate on violence, on the production of inequalities and on the disrespect of differences in daily school life. How can we face these conflicts in an indirect manner, dealing in a different way with demands for a fairer school, and thinking about practices that could help us to occupy a different place? In the research, we carried out a systematization of the theoretical debate on justice/injustice and a survey about the academic debate on the issue, both with their focus on the productions surrounding the school, in addition to two empirical studies. In the present text, that reflects necessarily a selection of results from a wider study, we describe perceptions about what is fair/unfair collected from students of the Pedagogy course of the Universidade de São Paulo, as well as from secondary education pupils, teachers and managers from a public school in São Paulo. These results were obtained from the analysis of the answers to a question that required describing a fair or unfair situation in the world and of a fair or unfair situation at school. We found a strong emphasis on the perception of injustice, both in the world and at school, corroborating the theoretical argument that what is positive is the perception of injustice. These perceptions are presented based on categories constructed in this study, and the article concludes with a brief description of proposals about what would constitute a fair school.
\end{abstract}

\section{Keywords}

Justice - Human rights - Violence - School - Equality - Difference.

I- Universidade de São Paulo, São Paulo,

SP, Brazil. Contact: oak1@uol.com.br 
0 projeto intitulado Direitos humanos, justiça e violência: percepções sobre a escola justa ${ }^{1}$ consistiu em uma pesquisa cujo objetivo geral foi articular a discussão sobre a redução e o tratamento da violência no ambiente escolar com a temática dos direitos humanos, tendo como foco a construção de uma escola justa. Para tanto, propôs-se um estudo que sistematizou os debates contemporâneos sobre o tema, com ênfase na tensão entre igualdade e diferença como elemento-chave para a construção de uma ideia de justiça; realizou-se também um estudo das pesquisas existentes sobre justiça e percepções de justiça/injustiça nos vários âmbitos da sociedade brasileira, com foco naquelas que tratavam do tema no cotidiano escolar; desenvolveu-se, ainda, uma pesquisa empírica a respeito das percepções de alunas(os) do curso de pedagogia da Faculdade de Educação da Universidade de São Paulo (FEUSP) e de professores(as) e alunas(os) de uma escola da rede pública (ensino médio) da cidade de São Paulo sobre o que seria uma escola justa.

Michel Foucault (2010) nos auxiliou na organização da perspectiva metodológica do trabalho a partir de sua análise dos focos de experiência ou matrizes da experiência, em sua vertente das formas de um saber possível. Segundo o autor, os focos de experiência articulam, uns sobre os outros, as formas de um saber possível, as matrizes normativas de comportamento para os indivíduos e os modos de existência para sujeitos possíveis (FOUCAULT, 2010). Essas três vertentes mantêm entre si relações simultaneamente heterogêneas, necessárias e irredutíveis: daí a possibilidade de analisar as vertentes da verdade, do poder e do sujeito como campos heterogêneos e interpenetrados, sobrepostos e em constante tensão e deslocamento uns em relação aos outros.

1- Pesquisa com financiamento do CNPq (Bolsa Produtividade em Pesquisa, 2009/2012). 0 projeto contou com duas iniciações científicas vinculadas, de Gabriela Marko e Vivian Valentim de Souza (ver Referências)

Tal perspectiva nos oferece a possibilidade de um trabalho constante de interrogação e problematização, bem como do uso de um conjunto de estratégias analíticas de descrição (LARROSA, 2002) que têm como foco o presente: como hoje se apresentam teorias e práticas; como estas são reconhecidas; como elas modelam, são apropriadas e transformadas pelos sujeitos em seu cotidiano institucional.

Cabe assinalar, no que concerne à nossa questão específica, a importância da inclusão das leituras de Derrida (2007, 1994), Ewald (1993), Fraser (2008), Ricoeur (2008), Heller (1998) e Arendt (2004), as quais são centrais para a discussão sobre a justiça e o justo, fazendo-se presentes direta ou indiretamente nas análises.

Retomando, havia como ponto de partida a constatação do impasse e da circularidade que cerca o debate sobre a violência, a reprodução das desigualdades e o desrespeito às diferenças no cotidiano escolar. Como tratar os conflitos que aí acontecem de forma, quem sabe, mais oblíqua, lidando de outra maneira com demandas por uma escola mais justa e pensando em práticas que podem nos permitir ocupar outro lugar? Ricoeur (2008) discorre longamente sobre a justiça como parte do conjunto de alternativas que a sociedade opõe à violência. A justiça se opõe tanto à violência aberta e reconhecida, quanto à violência dissimulada e sutil, assim como à violência da vingança (RICOEUR, 2008). 0 que seria, então, uma escola justa? É possível uma definição a priori? Seria ela aquela que trata de maneira integrada os direitos humanos em seu cotidiano? 0 que se compreende por direitos humanos nas escolas, com seu conteúdo de igualdade, reciprocidade, universalidade e respeito às diferenças? Qual é a relação entre direitos e justiça? Enfım, o que originou o debate que levou à pesquisa foi essa constatação de uma repetição e da existência de uma desarticulação entre temas que talvez componham uma vizinhança frutífera. 
Realizamos dois estudos empíricos sistemáticos sobre as percepções do justo/injusto. Tais estudos haviam sido precedidos por uma série de pesquisas anteriores, vinculadas a trabalhos de sala de aula em que discutíamos sobre a definição de uma escola justa. Alguns resultados obtidos a respeito do tema mostraram-nos quão difícil e desafiador é imaginar a escola justa, questão esta que é reconhecida na literatura sobre o assunto:

Ao contrário dos desastres que podem ser universalmente reconhecidos como prejudiciais e indesejáveis, uma vez que golpeiam a esmo e não prestam atenção a privilégios conquistados ou herdados, a justiça é um ponto notoriamente contencioso. (BAUMAN, 1998, p. 74)

Ponto contencioso que se apresenta precário e, ao mesmo tempo, urgente:

Ora, a justiça, por mais inapresentável que permaneça, não espera. Ela é aquilo que não deve esperar. Para ser direto, simples e breve, digamos isto: uma decisão justa é sempre requerida imediatamente, de pronto, o mais rápido possível. (DERRIDA, 2007, p. 51)

Trata-se de dilemas e possibilidades que permeiam a ação das escolas, mas que derivam de uma confıança primeira, ou seja, da existência de espaços de independência entre as esferas que fazem com que as escolas não reproduzam ou recriem cegamente as desigualdades e injustiças sociais:

A escola cria suas próprias desigualdades, a economia cria suas próprias desigualdades, a cultura cria suas desigualdades, a política cria suas desigualdades... as desigualdades de cada um desses domínios podem e precisam ser combatidas. Mas há desigualdades e injustiças novas quando as desigualdades produzidas por uma esfera de justiça provocam automaticamente desigualdades em outra esfera. (DUBET, 2004, p. 549)

Um sistema justo deveria assegurar certa independência entre essas esferas. Dubet sugere que tal independência pode existir e que as ações justas - ou que tendem a não reproduzir mecanicamente a injustiça - deveriam comportar uma combinação das ações listadas: modelo meritocrático, discriminação positiva, acesso a bens escolares fundamentais, um mínimo escolar, utilidade dos diplomas, atenção para que as desigualdades escolares não reproduzam as desigualdades sociais, bom tratamento dos vencidos. ${ }^{2}$

Nessa pesquisa sobre as percepções, ainda no pré-teste, conseguiu-se uma boa síntese de tal contencioso entre as(os) alunas(os) do curso de pedagogia: a justiça é vista como aquilo que é urgente, que recupera a irredutivel alteridade do outro, que estabelece a palavra em contraposição ao corpo a corpo, que é composto por elementos heterogêneos e que é sempre movimento, possibilidade.

Justiça é tratar com igualdade, mas não indiferença. É quando há igualdade de direitos e oportunidades. Quando há direitos respeitados, não apenas dos alunos, mas dos professores. Quando garante todos os direitos do ser humano. Uma escola justa pode ser aquela onde as coisas são decididas coletivamente. (Alunas(os) das disciplinas de Sociologia II e Educação e Atualidade, 2007)

Aparentemente singela, tal definição (construída coletivamente) toca em todos os aspectos sobre o quê, quem e como opera a justiça, bem como sobre seus impasses e desafios. Esse foi o ponto de partida para as pesquisas posteriores, que terão seus resultados brevemente apresentados a seguir.

2- Essas categorias orientaram a construção de uma das questões da pesquisa aqui apresentada. 


\section{Procurando percepções sobre a escola justa, encontramos percepçōes sobre a injustiça}

O grito "é injusto!" expressa muitas vezes uma intuição mais clarividente sobre a natureza verdadeira da sociedade e o lugar nela ocupado ainda pela violência, do que qualquer discurso racional ou razoável sobre a justiça. Paul Ricoeur

Para a pesquisa aqui relatada optou-se pela utilização de um questionário, por este configurar um instrumento quali-quantitativo muito interessante para coletar as percepções de grupos grandes. Além de uma primeira parte, com algumas questões que traçavam um perfil do respondente, havia duas questões abertas e uma terceira organizada a partir das propostas de Dubet (2004) sobre a escola justa, o que não trataremos neste breve artigo.

Uma primeira tomada de percepções sobre a escola justa ocorreu na própria Faculdade de Educação, com alunas(os) do primeiro ano de pedagogia (períodos vespertino e noturno) em 2010, totalizando 80 questionários respondidos. Foram elaborados quadros analíticos para analisar as respostas abertas, os quais foram organizados para detectar a escolha (situação justa/injusta): onde acontecia a situação narrada, com quem acontecia, qual era o princípio violado/atendido.

Realizamos também uma análise quantitativa do perfil dos respondentes. Trata-se de um público feminino $(82,5 \%)$ que já trabalha majoritariamente em educação (63,75\% já trabalham, dos quais 75\% atuam na área). Cabe ressaltar, ainda, outro aspecto do perfil das(os) alunas(os) da Faculdade de Educação: 40\% dos respondentes afirmou ter completado sua escolaridade integralmente na escola pública.

Realizamos e concluímos um segundo estudo empírico em uma escola estadual (no início de 2011) na zona sul da cidade de São Paulo, em Parelheiros, região com índices relevantes de pobreza e violência. A escola em questão foi escolhida por ser uma instituição de boa qualidade, sem problemas evidentes de violência ou outras queixas; uma escola em que as questões de acesso e qualidade de ensino são tratadas pela equipe de professores, gestores e dirigentes. Ali, colhemos e analisamos 81 questionários distribuídos entre alunos(as) da $3^{\text {a }}$ série do ensino médio regular, alunos(as) da $3^{\mathrm{a}}$ série do ensino médio da educação de jovens e adultos (EJA), professores(as) e gestores(as). Apresentaremos centralmente as percepções das(os) jovens.

Muito relevante é a presença marcante das meninas entre aqueles que concluem o ensino médio (66\%), superando a dos meninos. Esse é um dado importante, já conhecido a partir de outras pesquisas. As(os) alunas(os) do ensino médio regular estão na idade adequada: 28 tem 16 ou 17 anos (em 30 questionários respondidos). A idade dos alunos da EJA reflete perfis diferenciados (um grupo de estudantes que talvez estejam na condição de ir e vir da escola ao trabalho): são 12 entre 20 e 30 anos, contra 12 com mais de 30 , contando, entre estes últimos, pessoas de 40 e 50 anos, no total de 27 questionários respondidos.

A questão que queremos comentar aqui é a da presença dominante de relatos de injustiça perante a pergunta que foi proposta para os respondentes em dois níveis, em relação ao mundo em geral e à escola: "Faça um breve relato sobre uma situação reconhecida por você como justa ou injusta. Diga onde, com quem, circunstâncias, resultado".

No caso das(os) alunas(os) de pedagogia, das 160 respostas possíveis, foram apresentadas 131 situações injustas, o que representa, portanto, $81,8 \%$. No caso da E.E.P.N.E., 133 das 162 respostas possuem tal característica, ou seja, 82\% do total. Já a justiça aparece em 22 relatos das(os) alunas(os) de pedagogia $(13,7 \%)$ e em 24 respostas vindas da E.E.P.N.E (14,8\%). 0 dado, então, é o seguinte: no caso da E.E.P.N.E., se são relatados 7 situações de justiça no mundo (8,6\%), sobre a escola aparecem 17 (20,9\%); já no caso do curso de pedagogia, o número de relatos de 
justiça no mundo e na escola é exatamente o mesmo (13,7\% para cada uma das situações). ${ }^{3}$

Quadro 1 - Onde estão as injustiças? (Pedagogia)

\begin{tabular}{l|ccc}
\hline Onde & Injusto & Justo \\
\hline No mundo & $80 \%$ & $13,7 \%$ \\
\hline Na escola & $\vdots$ & $82,5 \%$ & $13,7 \%$ \\
\hline
\end{tabular}

Quadro 2 - Onde estão as injustiças? (E.E.P.N.E.)

\begin{tabular}{l|c:c}
\hline Onde & Injusto & Justo \\
\hline No mundo & $86,4 \%$ & $8,6 \%$ \\
\hline Na escola & $77,7 \%$ & $20,9 \%$ \\
\hline
\end{tabular}

Daí o título deste tópico: fomos em busca da escola justa e encontramos um relato de injustiças repercutindo e confirmando as afırmações de vários teóricos sobre a justiça (RICOEUR, 2008; BAUMAN, 1998; MOORE JR., 1987; DERRIDA, 2007). Afirma Ricoeur (2008, p.85): "De fato, nosso senso de injustiça costuma ser mais confiável do que nosso senso de justiça”. Em sua análise, o autor retoma a tradição de Platão e Aristóteles ao situar o injusto como anterior ao justo:

Nosso primeiro ingresso na região do direito não terá sido marcado pelo grito: É injusto! É esse o grito da indignação [...] ora, procuremos lembrar quais foram as situações em que nossa indignação se inflamou. Foram, por um lado, as das divisões desiguais, que achávamos inaceitáveis [...]. Foram, por outro lado, as das promessas não cumpridas [...] foram, também, as das punições que nos pareciam desproporcionais [...]. Retribuições desproporcionais, promessas traídas, divisões desiguais [...]. Mais que isso: não discernimos na indignação uma expectativa precisa, a da palavra que instauraria entre os antagonistas a

3- Há relatos que contemplam ambas as situações e há alguns que não responderam a uma ou a outra questão. Daí os totais não coincidirem (lembrando que o total do curso de pedagogia é de 80 questionários e 0 da E.E.P.N.E. é de 81). justa distância que daria fim a seu corpo-a-corpo? Nessa confusa expectativa da vitória da palavra sobre a violência consiste a intenção moral da indignação. (p. 5)

Foi o que constatamos extensamente nessa primeira pesquisa. Citando Barrington Moore Jr. (1987), Bauman (1998, p. 75) comenta:

Sabemos, pela meticulosa e perceptiva análise histórica conduzida por Barrington Moore Jr., que ao mesmo tempo em que as “massas" não fazem idéia ou, na melhor das hipóteses fazem uma idéia vaga, da noção abstrata de "justiça como tal", elas tendem a reconhecer infalivelmente um caso de injustiça. Em oposição ao que a lógica do vocabulário sugere, "injustiça" é uma noção "positiva”, enquanto "justiça" é a negativa.

Prossegue o autor:

É a injustiça que parece ser a noção primária da ética popular, sendo a "justiça" a unidade marcada, um derivado, na oposição [...] justiça significa redenção, recuperação do dano, compensação pelos males sofridos - que corrija a distorção causada pelo ato de injustiça. [...] é difícil dizer sob que condições a percepção popular da condição humana como justa e correta tenderá a se desenvolver e é incerto se tal desenvolvimento, caso ocorra, será sujeito a normas verificáveis e generalizáveis. Por outro lado, pode-se razoavelmente supor que a percepção da situação como injusta tenderá a expandir-se e aprofundar-se juntamente com a intensificação das provações não experimentadas antes. ${ }^{4}$

4- Moore Jr., interessado em entender as "bases sociais da obediência e da revolta", tentará, via estudo das injustiças, compreender como as normas sociais e sua violação são componentes centrais da ira moral e do sentido de injustiça. Ele aponta também para o surgimento da indignação e da revolta no fato de que a própria norma social pode ser vista como injusta e errada (MOORE JR., 1987, p. 21). Resgata, assim, o marco que não contém a justiça, mas que é inseparável de nossa possibilidade de pensar a justiça ou a injustiça. É sempre com relação a alguma norma, algum direito ou alguma lei que nos posicionamos em nosso grito de indignação. 
A percepção da injustiça, assim, é o positivo, ou seja, aquilo que é perceptível. Tal fato é confirmado quando levantamos o número de questões que relatam situações de injustiça, comparando as que tratam da injustiça no mundo em geral e as que tratam da injustiça na escola. Seria de se esperar que houvesse uma percepção maior de injustiça no mundo do que na escola, e que esta fosse um lugar a respeito do qual os relatos de injustiça se veriam ofuscados pelos de justiça. Não foi esse o resultado que encontramos, mesmo no caso da escola pública e especificamente no dos alunos da EJA, que consideram sua escola como modelo de escola justa.

Apresentaremos a seguir os resultados das pesquisas a partir de seus eixos principais: injustiças no mundo e injustiças na escola. Conseguimos organizar as informações em torno de alguns grandes eixos: a) Macrojustiça ou microjustiça? b) Onde as injustiças acontecem? c) Quais são os conflitos? d) Quem sofre a injustiça?

\section{Injustiça no mundo}

\section{Macrojustiça ou microjustiça? ${ }^{5}$}

Um primeiro elemento interessante que queremos ressaltar é como se dá a percepção da macroinjustiça, da injustiça social ou da microinjustiça, aquela do cotidiano, ligada às relações interpessoais em instituições como o trabalho ou a família.

No curso de pedagogia, das 80 respostas, conseguimos identificar $30(37,5 \%)$ que classificamos como correspondendo à percepção de macroinjustiça. Uma resposta típica desse caso pode ser a seguinte:

Considerando a situação de exploração econômica das classes populares no Brasil,

5- Apresentaremos as respostas identificadas como: $\mathrm{FE}=$ alunas(os) da Faculdade de Educação; $E$ = alunos do ensino médio da E.E.P.N.E.; EJA = alunos de EJA dessa mesma escola; $\mathrm{G}$ ou $\mathrm{P}$ = professores e gestores da escola. sobretudo com a ampliação da terceirização, é injusta a fiscalização e apreensão das mercadorias dos trabalhadores informais da Rua 25 de Março, visando o benefício dos comerciantes locais que recolhem imposto para o governo. (FE5)

\section{Outro exemplo:}

Ver a individualidade e a ignorância de uma sociedade doente onde as condições de vida são determinadas pela origem financeira, onde os direitos à qualidade de vida são privilégios de poucos. (FE6)

Trata-se, com certeza, de estudantes com um perfil diferenciado que tentam pensar as questões sociais. Mesmo assim, a maioria deles relatou casos de microinjustiça (50\%), como o seguinte:

Quando eu estava na terceira série de ensino fundamental, minha mãe trabalhava e meu pai também, por isso não podiam me levar à escola; minha mãe decidiu pagar alguém para me levar. 0 tio deixava a todos na porta de suas casas, mas como eu morava em uma favela, ele me deixava na entrada da favela (longe de casa) porque se recusava a entrar naquele lugar (como ele disse à minha mãe). (FE10)

É claro que há relação entre ambos os tipos de relato: os exemplos de microinjustiça refletem macroinjustiças, preconceito social e preconceito racial, por exemplo. Vale lembrar as palavras de Bauman (1998, p.90):

Tanto a moralidade como a justiça (ou, como prefeririam alguns, a micro-ética e a macro-ética) são fiéis a seu nome somente como condições contingentes e projetos cônscios de sua contingência. [...] permitam-me repetir que a cena moral primordial, a reunião moral de dois, é o terreno em que se cultiva toda responsa- 
bilidade para com o Outro e o terreno de aprendizado para a ambivalência necessariamente contida na pressuposição dessa responsabilidade. Sendo assim, parece plausível que a chave para um problema tão vasto quanto a justiça social reside em um problema tão (ostensivamente) diminuto quanto o ato primordial de assumir responsabilidade para com o Outro próximo, a pequena distância - para com o Outro enquanto Rosto.

Cabe salientar que, na E.E.P.N.E., encontramos apenas 15 relatos com cunho social, apontando para injustiça ou desigualdade social $(18,5 \%)$, contra $60(75 \%)$ relatos de microinjustiças, em um total de 81 respostas. Um exemplo: "Vemos no mundo muitos políticos, pessoas da classe alta, que roubam os pobres e não são punidos" (E13). ${ }^{6}$

É certo que aquilo que vivemos no dia a dia é o que mais nos toca, indigna, mobiliza. Bauman (1998) é bastante enfático em sua defesa de que a busca por justiça social inicia-se exatamente nesse momento de indignação pelo outro próximo, pelo outro que vemos.

Outros casos ilustrativos disso são:

Quando duas meninas estavam abraçadas em uma vila e apareceu um homem falando um monte de coisas, achando que elas eram um casal. Eu acho que foi injusto. (E1).

Certo dia estava em um ponto de ônibus e lá tinha um garoto deficiente físico e quando o ônibus parou as pessoas quase passaram por cima dele. Essa é uma situação injusta. (EJA40)

Aquilo que é próximo toca-nos, mobilizanos e aguça nossa percepção sobre a injustiça.

6- Afirma Barrington Moore Jr. (1987, p.64): "Uma das fontes mais poderosas de indignação moral é ver alguém escapar impunemente ao desrespeitar uma regra moral que as pessoas fizeram dolorosos esforços para torná-la parte de seu próprio caráter".

\section{Onde as injustiças acontecem?}

Novamente no que concerne aos relatos de justiça/injustiça no mundo, quais são os lugares mais citados como palco das cenas de injustiça?

\section{Quadro 3 - As injustiças do mundo}

\begin{tabular}{l|c:c}
\hline Onde & $\begin{array}{c}\text { Pedagogia } \\
\text { (total = 80) }\end{array}$ & $\begin{array}{c}\text { E.E.P.N.E } \\
\text { (total = 81) }\end{array}$ \\
\hline Trabalho & $12-15 \%$ & $7-8,6 \%$ \\
\hline Rua & $14-17,5 \%$ & $12-14,8 \%$ \\
\hline Transporte público & $4-5 \%$ & $13-16 \%$ \\
\hline Casa & $6-7,5 \%$ & $2-2,4 \%$ \\
\hline Universidade pública & $10-12,5 \%$ & $2-2,4 \%$ \\
\hline Sociedade & $10-12,5 \%$ & $8-9,8 \%$ \\
\hline Serviço medico & $2-2,5 \%$ & $6-7,4 \%$ \\
\hline Universidade particular & $3-3,7 \%$ & - \\
\hline Escola & $4-5 \%$ & $14-17,2 \%$ \\
\hline $\begin{array}{l}\text { Outros (comércio, esporte, } \\
\text { museu, partido político }\end{array}$ & $6-7,5 \%$ & $2-2,4 \%$ \\
\hline Banco & \multicolumn{1}{c}{-} & $6-7,4 \%$ \\
\hline Justiça/justiça penal & $1-1,2 \%$ & $3-3,7 \%$ \\
\hline
\end{tabular}

As diferenças podem ser compreendidas a partir das particularidades das experiências. Mesmo que os alunos da E.E.P.N.E. sejam do $3^{\circ}$ ano, jovens já em busca ou preocupados com o trabalho/emprego, sua diferença de idade em relação aos alunos de pedagogia e o fato de a grande maioria já trabalhar fazem com que as relações de trabalho apareçam eivadas de injustiça. ${ }^{7}$

Alguns exemplos:

Atitude persecutória em ambiente profissional, injusta e não resolvida, criando dificuldades não revelando dados do trabalho, mas cobrando-os e criando dificuldades gerais para o exercício das atividades,

7- Assmar (1997), em sua pesquisa sobre injustiça com três grupos sociais, detecta o local de trabalho como principal cena de ocorrência de injustiça $(23,9 \%)$, seguido da família e da escola $(21,2 \%)$. É claro que essa percepção depende da situação do grupo (trabalhadores ou não, empregados ou não). E é interessante que a família não tenha aparecido com esse destaque em nossa pesquisa. 
por mera antipatia ou envolvimento afetivo com determinadas pessoas. (FE28)

Uma situação injusta é quando em uma entrevista para uma vaga de emprego uma pessoa não tem a igualdade de possibilidade de alcançar a vaga por ser negra e não ter o padrão de beleza considerado ideal, sendo descartada sem ter sequer a possibilidade de mostrar suas habilidades e competências. (FE44)

Até agora eu nunca fui chamado para um trabalho, mas eu queria tanto ter um, é um dos meus sonhos. (E28)

A arbitrariedade e a injustiça no ambiente de trabalho são destaque nos relatos, principalmente entre aqueles que vivem o cotidiano das empresas atuais.

A rua é a grande cena das injustiças: moradores de rua, crianças nos faróis, assaltos, desrespeito ao pedestre, agressões físicas e verbais, discriminação, abordagem policial. Em tal cenário, um aspecto importante a ser observado são as injustiças do transporte público, presentes em muitos relatos de desrespeito em ônibus e trens. 0 desrespeito a idosos e mulheres com crianças de colo também foi um caso recorrente nas respostas:

já aconteceu uma situação injusta: jovens sentados no ônibus enquanto pessoas idosas ficam em pé. Isso não deveria acontecer. (EJA 38)

A injustiça na casa ou na família foi pouco percebida. Porém, dois relatos dizem o seguinte:

minha família é meio injusta às vezes, pois já tive ideias muito boas sobre assuntos de família e ninguém quer me ouvir, pois acham que eu sou nova demais. (E7)

Injustiça: minha mãe diz que, quando pequena, sempre que ela ou algum dos seus quatro irmãos faziam algo de errado, minha avó batia em todos eles por não saber quem tinha feito a arte, para dar exemplo aos outros, ou porque achava que os outros tinham sido cúmplices. (FE13)

Seria a família realmente o porto seguro no meio das injustiças das ruas, dos serviços públicos, do transporte?

0 aparecimento da universidade pública como palco de cenas de injustiça deve-se ao intenso debate sobre ações afirmativas, cotas e bônus para ingresso no vestibular, debate este que também questiona quem está na universidade pública e o modo como se dá a seleção pós-fuvest:

Algumas bolsas de iniciação científica (importantíssimas para a vida acadêmica) chegam a R\$ 500,00, mas geralmente são em torno de $\mathrm{R} \$ 300,00$, impedindo quem a recebe de trabalhar, o que seleciona os alunos da classe alta ou deixa em situação de miséria os alunos da classe baixa que possam realizá-las. (FE11)

A forma como o vestibular é feito dificulta o acesso de pessoas com menor renda e que sempre estudaram em escola pública e que não tiveram condições de fazer uma preparação específica para esse exame. Sendo assim, uma situação injusta. (FE15)

Esse foi um tópico pouco presente nos relatos provenientes da escola E.E.P.N.E., mesmo que alguns estudantes tenham reclamado da injustiça do vestibular. Mais recorrentes foram os casos de injustiça no serviço médico e nos bancos (ligados a preconceito e discriminação):

tive uma situação injusta em um hospital quando minha mãe estava com câncer e o hospital não tinha vaga para internar e então eu fui à luta até eu conseguir porque a paciente não podia ficar em casa. A situação era muito difícil. (EJA 53) 
As denúncias sobre a injustiça do sistema criminal também foram mais presentes entre os estudantes da E.E.P.N.E. Tais situações também apareceram nos relatos das estudantes de pedagogia, mas manifestaram-se em acontecimentos de rua em que policiais abordam jovens para revistá-los, discriminando aqueles que são negros ou pardos. Há, assim, uma denúncia clara de discriminação racial.

\section{Quais são os conflitos?}

Na pesquisa de Venturi (2010), vimos que a frase que obteve maior adesão foi respeito é bom e todo mundo merece, apoiada por $98 \%$ dos entrevistados.

A questão respeito/falta de respeito aparece fortemente nas falas coletadas, principalmente por parte dos estudantes da E.E.P.N.E., e é um elemento fundamental no sentimento de justiça/injustiça detectado. Foram 45 menções ao respeito/desrespeito (55,5\%) nos relatos da E.E.P.N.E, contra 27 (33,7\%) entre as(os) alunas(os) de pedagogia. Tal temática aparece associada à situação dos idosos - principalmente no transporte público ou em atendimentos preferenciais -, dos deficientes físicos e daqueles que têm outros padrões de beleza, bem como às diferenças de orientação sexual, cor e origem social. Ou seja, ela aparece nos relatos de situações de injustiça entre as pessoas em seu cotidiano, refletindo o desrespeito a direitos perante a saúde, a justiça penal e o direito de ir e vir.

Há também desrespeito ao princípio da igualdade, que comparece em todos os planos de descrição de injustiças. Propomos agora uma nova leitura do material apresentado nas respostas à questão sobre a justiça/injustiça no mundo a partir de algumas categorias, todas elas denotando diferentes sentidos à violação de algum princípio de igualdade:

a) injustiças ligadas à discriminação (reconhecimento): aqui trabalhamos com todas as expressões de discriminação racial, por orientação sexual, por aspecto físico, idade, naturalidade, origem regional, local de moradia;

b) injustiças ligadas à desigualdade social (distribuição): aqui incluímos todas as queixas de injustiça ligadas à desigualdade de direitos e de acesso a direitos na forma de bens e serviços;

c) injustiças ligadas à retribuição (de bens ou punições - merecimento): aqui organizamos as respostas com menções à injustiça caracterizadas pela ideia de que ela/ele não merecia;

d) injustiças ligadas à violação da igualdade perante a lei e as regras (dois pesos e duas medidas): quando não há simetria ou reciprocidade em relação a leis ou regras; daí a expressão que sintetiza essa indignação: dois pesos e duas medidas, variando de acordo com status, classe social, poder, riqueza, autoridade, beleza etc.;

e) injustiças ligadas à violência criminal: constituem um item a parte, que aparece com mais força na E.E.P.N.E. em relatos de assaltos, agressões etc.;

f) injustiças ligadas à violência policial.

Essas categorias necessariamente se entrecruzam, ligam-se entre si, suportam-se mutuamente, amplificam-se. Nos relatos, há mais de uma indicação de categoria; há casos de desigualdade que geram situações de discriminação, mas eles permitem, porém, certo desenho do material para sua visualização e compreensão.

\section{Quadro 4 - Categorias da injustiça}

\begin{tabular}{|c|c|c|}
\hline Tipo & $\begin{array}{l}\text { Pedagogia } \\
\text { (total }=80)\end{array}$ & $\begin{array}{l}\text { E.E.P.N.E. } \\
(\text { total }=81)\end{array}$ \\
\hline $\begin{array}{l}\text { Discriminação/reconhecimento } \\
\text { falho }\end{array}$ & $15-18,7 \%$ & $21-25,9 \%$ \\
\hline Distribuição/desigualdade & $22-27,5 \%$ & $5-6,1 \%$ \\
\hline Retribuição (não merecia) & $25-31,2 \%$ & $25-30,8 \%$ \\
\hline $\begin{array}{l}\text { Igualdade perante a lei/regra } \\
\text { (dois pesos e duas medidas) }\end{array}$ & $5-6,2 \%$ & $15-18,5 \%$ \\
\hline Violência criminal & $2-2,5 \%$ & $6-7,4 \%$ \\
\hline Violência policial & $2-2,5 \%$ & $1-1,2 \%$ \\
\hline
\end{tabular}

É na situação em que há uma retribuição injusta (um castigo, um favorecimento a alguém que não parece merecê-lo) que o sentimento 
de indignação se revela mais forte. 0 que lhe cabe? 0 que lhe é devido? Qual é o seu lugar? Lembramos que esse é um dos pontos centrais dos dilemas da justiça.

Assmar (1997, p.4), em sua análise da injustiça na vida diária, estudando percepções de três grupos sociais, ${ }^{8}$ questiona que o grande fator de mobilização em torno da justiça seja a luta por equidade:

a aparente "dessensibilização" à injustiça, demonstrada pelos sujeitos brasileiros, pode estar indicando que a crença na proporcionalidade talvez não seja tão universal.

A autora levanta várias hipóteses para esse fato, tais como: a falta de confiança de que o esforço, a tenacidade e a competência conduzem a bons resultados; a percepção da impunidade para aqueles que violam as regras e levam vantagem; e os efeitos das mudanças constantes nos planos econômicos e nas políticas públicas, alterando as regras do jogo.

Sua pesquisa indica que a maior frequência de experiências de injustiça é de "acusação ou censura injustificada” (33,3\%), seguida pela "avaliação injusta ou não reconhecimento do esforço ou desempenho" (14,4\%), pela "punição injustificada" (10,7\%) e pela "traição de confiança” (9,7\%) (ASSMAR, 1997, p. 6).

Há, assim, coincidência entre as pesquisas, pois estamos chamando de retribuição injusta esse conjunto que também é falado pelos depoentes com a caracterização de ele(a) não merecia. Cabe assinalar que, ao contrário de nossa pesquisa, que não procurou saber quais foram as reações à injustiça, na pesquisa de Assmar, a subcategoria mais encontrada foi "não fazer nada", "aceitar ou resignar-se à injustiça” (34,4\%). É interessante perceber que o grupo mais resignado foi o dos adolescentes $(39,7 \%)$, seguido pelo grupo dos estudantes universitários $(37,7 \%)$ e, por último, pelo grupo dos trabalhadores (25,9\%). Essa passividade

8- A autora trabalhou com relatos de injustiça de 99 adolescentes, 100 universitários e 98 trabalhadores. perante a injustiça é um dado a ser pesquisado que pode relacionar-se aos elementos da pesquisa de Venturi (2010) sobre a fraca percepção de um quem que pudesse mudar a situação de desigualdade e injustiça.

\section{Quem sofre a injustiça?}

É difícil colocar-se na posição de vítima de injustiça, de discriminação e de desrespeito, e relatar um caso que tenha nos acontecido. Assim, a maioria dos relatos trata de situações que envolvem um outro genérico ou um outro próximo. Eles falam de uma amiga, meu grupo, os alunos, os moradores de rua, os estudantes.

Quadro 5 - Quem sofreu a injustiça?

\begin{tabular}{l|c:c}
\hline Com quem aconteceu? & Pedagogia & E.E.P.N.E. \\
\hline Comigo & $6 \%$ & $7 \%$ \\
\hline Com 0 outro próximo & $23 \%$ & $40 \%$ \\
\hline Com 0 outro genérico & $56 \%$ & $44 \%$ \\
\hline
\end{tabular}

Alguns exemplos:

Acredito que uma situação injusta com a qual me deparo todos os dias é a dos moradores de rua. (FE1)

Injusta: vi na televisão, uma senhora caminhava num asilo e foi agredida por uma enfermeira. Resultado: a pobre senhora cheia de hematomas e com depressão profunda. A velhice no capitalismo é algo para se preocupar, sei que um dia poderá acontecer comigo ou com qualquer um. (FE2)

Há alguns relatos sobre injustiça com outros próximos, alguém da família, colegas de trabalho, amigos:

dois amigos meus, mulatos, foram parados por um carro da polícia na volta de um trabalho voluntário. Os dois estavam com camisetas do trabalho e quando eu e 
minha irmã (ambas loiras) paramos atrás deles para saber o que estava acontecendo, os guardas liberaram eles no mesmo momento. (FE18)

Um relato pessoal foi o seguinte:

uma situação injusta que vivi foi quando fui assaltada a caminho do cursinho prévestibular. Duas pessoas me pararam e roubaram meu celular. (FE37)

Outro exemplo: "negaram um emprego por causa da falta de experiência” (E6).

0 sofrimento ligado à experiência de injustiça pessoalmente vivida faz com que seja difícil falar: quando contamos alguns casos ligados à família, a alguma situação pessoal concreta que envolve discriminação e humilhação, não é possível sequer contar. Isso faz com que relatemos casos de injustiça que vimos na condição de testemunhas.

\section{Injustiça na escola}

Descreveremos a seguir o perfil das respostas sobre injustiça na escola. Lembramos que temos, do curso de pedagogia, em relação aos relatos sobre o justo/injusto, um total de 80 questionários que ficaram assim distribuídos: $82,5 \%$ contêm relatos de injustiça na escola e 13,7\% apresentam situações de justiça. Na E.E.P.N.E., temos um total de 81 questionários com respostas sobre o justo/injusto na escola e eles se distribuem assim: 77,7\% contêm relatos de injustiça e 20,9\% de situações percebidas como justas.

\section{Onde acontecem os conflitos?}

Como era esperado, o lugar dos conflitos é a sala de aula. Há, porém, interessantes diferenças de percepção entre os respondentes da escola pública e os respondentes da universidade, que se expressam no quadro a seguir.
Quadro 6 - Onde acontecem as injustiças na escola?

\begin{tabular}{l|c:c}
\hline Onde & $\begin{array}{c}\text { E.E.P.N.E. } \\
\text { (total = 81) }\end{array}$ & $\begin{array}{c}\text { Pedagogia } \\
\text { (total = 80) }\end{array}$ \\
\hline Sala de aula & $25-30,8 \%$ & $51-63,7 \%$ \\
\hline $\begin{array}{l}\text { Banheiro, corredor, entrada, } \\
\text { cantina, pátio }\end{array}$ & $13-16 \%$ & $3-3,7 \%$ \\
\hline $\begin{array}{l}\text { Sala da direção } \\
\text { Fora da escola: excursão, } \\
\text { estacionamento, transporte }\end{array}$ & $3-3,7 \%$ & $2-3,7 \%$ \\
\hline $\begin{array}{l}\text { Na escola em geral, no sistema } \\
\text { escolar }\end{array}$ & $25-30,8 \%$ & $10-12,5 \%$ \\
\hline
\end{tabular}

Para as(os) alunas(os) de pedagogia, muitas(os) das(os) quais já trabalham em educação, o espaço central do conflito e o lócus das situações de injustiça é a sala de aula. Já os respondentes da E.E.P.N.E. têm um perfil mais amplo: são estudantes, professores e gestores. Entre os professores, aparece uma crítica geral da injustiça do sistema escolar, que discrimina o professor. Há vários depoimentos sobre a injustiça da progressão continuada, das formas de avaliação, das condições de trabalho. 0 problema não estaria na sala de aula, mas sim no sistema. Os alunos da escola, por outro lado, vivenciam fortemente os conflitos na sala de aula. Porém, na escola pública há, também, uma percepção de conflitos aparecendo fora da sala de aula e envolvendo relações entre alunos. Essa percepção não aparece entre as(os) estudantes de pedagogia.

A exemplo disso, um aluno de EJA diz:

eu gostaria que os professores tomassem uma atitude com os alunos que ficam bagunçando dentro da sala e atrapalham os outros colegas que saem de casa para vir estudar. (EJA52)

Esse mesmo aluno, ao comentar como seria para ele a escola justa, declara:

Uma escola limpa e organizada, uma coordenação que age na hora certa e sempre tenta ajudar os alunos que estão com dificuldade para aprender e sempre orientar os alunos para não riscar as carteiras. (EJA52) 
A fila supõe um complexo de normas socialmente estabelecidas, refletindo critérios e percepções de justiça (IGLESIAS; GÜNTHER, 2007). Ela é, assim, um dos lugares onde há conflitos.

Todos os dias vamos lanchar no refeitório da escola e temos que pegar fila, porém tem pessoas que cortam essa fila fazendo assim que a pessoa que já estava na fila fique para trás. Essa situação também é injusta. (E14)

As agressões entre alunos aparecem em vários depoimentos. Um deles nos diz:

desde quando eu entrei na escola meu amigo só apanhava, quando não até agora só apanha e nós amigos dele tem que proteger ele. (E28)

Quando questionado sobre o que seria uma escola justa, o mesmo aluno responde:

Para mim uma escola justa não seria nada. Porque tem muitos alunos que não ligam para as aulas. (E28)

Está dada, para ele, a impossibilidade de uma escola justa, pois faltaria um dos atores centrais para que esta acontecesse, ou seja: os estudantes que ligassem para as aulas.

\section{Quem está envolvido?}

É interessante olhar os dados à luz de quem está envolvido nos conflitos.

Quadro 7 - Quem protagoniza?

\begin{tabular}{l|c:c}
\hline Quem & $\begin{array}{c}\text { E.E.P.N.E. } \\
\text { (total = 81) }\end{array}$ & $\begin{array}{c}\text { Pedagogia } \\
\text { (total = 80) }\end{array}$ \\
\hline Alunos \& professores & $21-25,9 \%$ & $46-57,5 \%$ \\
\hline Alunos \& direção/gestão & $7-8,6 \%$ & $8-10 \%$ \\
\hline Alunos \& alunos & $18-22,2 \%$ & $1-1,2 \%$ \\
\hline Comunidade \& escola & $2-2,4 \%$ & $3-3,7 \%$ \\
\hline Alunos \& sistema escolar & $1-1,2 \%$ & $10-12,5 \%$ \\
\hline Professores \& sistema escolar & $11-13,5 \%$ & - \\
\hline
\end{tabular}

Os conflitos são narrados com dor e paixão:

Quando uma aluna avisou o professor que estava faltando um ponto de interrogação em uma frase e o professor se sentiu ofendido por causa disso, e a ofendeu, chamando-a de macaca. (E1)

É lógico que, quando o questionário solicita a defınição do que seria uma escola justa, tal aluna afirma: "sem preconceito, onde todos tivessem os mesmos direitos e deveres" (E1).

Há os exemplos clássicos: "na sala de aula, quando alguns alunos bagunçam, toda a sala é punida" (E8). Uma aluna de EJA relata um caso parecido:

minha filha cursa a quinta série e, na semana passada, ela ficou sem poder ir a uma excursão que a escola está promovendo porque um colega da sala dela, durante uma aula vaga, quebrou um vidro da janela e a sala toda foi castigada, mesmo sabendo quem foi o autor da bagunça. Isso é injusto. (EJA33)

Para essa estudante, a escola justa seria assim:

é onde todos nós teríamos os mesmos ensinamentos que as escolas particulares, desde lições, materiais para os professores trabalhar, ambiente, resumindo, se é escola, independente de tudo, deveria ser igual "por dentro". (EJA33)

É interessante ver a forte demanda por igualdade aí presente: tudo deveria ser igual por dentro.

Cabe também transcrever o depoimento de uma professora que pode exemplificar os conflitos entre professores e sistema:

promover o aluno sem conhecimento algum, sistema de ciclo implantado nas escolas públicas, falta de reconhecimento dos professores, falta de incentivo 
para que possam estar constantemente em formação, estudando para sempre melhorar seus conhecimentos para os alunos. (P59)

Uma aluna de pedagogia faz o seguinte relato:

na escola onde eu trabalho, presenciei uma situação que considero não só como injusta, mas preconceituosa também. Um aluno pediu para sentar-se na frente, pois havia esquecido seus óculos e a professora disse que não tinha culpa dele ser um ceguinho e o mandou para a última carteira. (FE10)

\section{Outra história:}

no segundo ano do ensino médio um aluno considerado ruim (que senta no fundo da sala e não faz as lições) chegou atrasado na sala de aula, após o intervalo e disse à professora que havia ido beber água e ficado trancado no pátio. Ela não acreditou e pediu para ele descer até a diretoria. Ele, imediatamente, apontoume e disse que se a história fosse minha, ela acreditaria (eu era tida como uma boa aluna). Então, a professora disse: de fato, acreditaria. (FE13)

Antes de concluir o comentário a esse respeito, lembramos que, para os(as) professores(as) que responderam ao questionário, a maior parte da injustiça está fora da escola e da sala de aula. Segundo tais professores(as), a injustiça é contra eles como profissionais; ela é diária, constante, expressa-se nos baixos salários e em sua desvalorização profissional, e seu grande agente é o sistema escolar. Não há, aparentemente, uma percepção de que a atuação que eles próprios têm em sala de aula possa gerar injustiças. Eles(as) são os(as) injustiçados(as). Essa é uma questão que merece uma maior investigação.

\section{Quais são os conflitos?}

Cabe apenas, agora, apontar quais são os conflitos mais detectados como geradores de situações injustas.

Quadro 8 - Categorias da injustiça na escola

\begin{tabular}{|c|c|c|}
\hline 0 quê & $\begin{array}{l}\text { E.E.P.N.E. } \\
(\text { total }=81)\end{array}$ & $\begin{array}{l}\text { Pedagogia } \\
\text { (total }=80 \text { ) }\end{array}$ \\
\hline Discriminação & $1-1,2 \%$ & $11-13,7 \%$ \\
\hline $\begin{array}{l}\text { Ausência de reciprocidade (dois } \\
\text { pesos e duas medidas) }\end{array}$ & $8-9,8 \%$ & $1-1,2 \%$ \\
\hline $\begin{array}{l}\text { Avaliação injusta, punição } \\
\text { injusta ou ausência de punição } \\
\text { (retribuição injusta: não merecia) }\end{array}$ & $33-40,7 \%$ & $36-45 \%$ \\
\hline $\begin{array}{l}\text { Falta de diálogo, não querer } \\
\text { ouvir, negativa da palavra }\end{array}$ & $12-14,8 \%$ & $5-6,2 \%$ \\
\hline $\begin{array}{l}\text { Injustiça social e injustiça } \\
\text { escolar, desigualdade social e } \\
\text { desigualdade escolar }\end{array}$ & $3-3,7 \%$ & $13-16,2$ \\
\hline $\begin{array}{l}\text { Violência física, bullying, } \\
\text { agressão verbal }\end{array}$ & $10-12,3 \%$ & $4-5 \%$ \\
\hline Desrespeito às normas e às leis & $10-12,3 \%$ & $4-5 \%$ \\
\hline
\end{tabular}

Chama a atenção a diferença de olhar entre as(os) alunas(os) de pedagogia e alunos, professores e gestores da escola em relação à discriminação. 0 olhar das(os) estudantes da faculdade é aguçado: há tanto relatos pessoais sobre discriminação sofrida como relatos ocorridos nas escolas onde trabalham. Na E.E.P.N.E., isso não é apontado. Houve relatos de discriminação no mundo ligados a cor, orientação sexual, idade, origem regional, mas na escola, na sala de aula, isso não é tematizado. A questão apenas aparece, talvez, muito lateralmente em algum relato de uma retribuição (punição) injusta. Em tal contexto parece ser mais difícil falar sobre a discriminação.

A retribuição injusta (punição excessiva ou falta de punição) é a grande questão: a que envolve a avaliação, a medida. Qual é a medida justa? É possível imaginar que esse item, que compõe o cerne da injustiça na escola, pode estar associado à ausência de diálogo, à queixa reiterada de ausência de possibilidade de dizer o que se pensa sobre 
as regras, sobre as decisões. Lembramos que, no item retribuição, encontram-se também todos os depoimentos que dizem da necessidade de punir aqueles que fazem bagunça: seja a falta ou o excesso de punição, qualquer uma das duas situações se configura como injusta.

A ausência de reciprocidade (o professor que cobra a matéria que não deu, por exemplo) é muito presente na escola, assim como as situações de violência direta e quebra de regras ou leis. A quebra de regras ou normas internas é bastante comum nos relatos, combinando-se com as respostas que mencionam o uso de dois pesos e duas medidas. Um exemplo disso pode ser o seguinte:

uma situação injusta que acontece sempre é ser adiado o dia de entregar o trabalho que o professor propôs, porque parte da sala não fez, valendo a mesma nota para todos ou quebrando a igualdade de todos terem o mesmo tempo para fazer o trabalho. (FE62)

Há aí a quebra de um combinado, o que leva a uma retribuição injusta, pois alguns terão maior tempo para a tarefa e não obterão desconto na nota pelo atraso. Configura-se, portanto, a violação da ideia de valorização do mérito (esforço, pontualidade, disciplina).

Vejamos outro exemplo que ilustra a retribuição injusta por conta de dois pesos e duas medidas:

quando eu cursava a sexta série, uma colega de classe, assim como todos os demais colegas, fez um trabalho, um desenho, para a disciplina de Educação Artística. 0 trabalho ficou realmente lindo, bem feito, harmônico, fenomenal! No entanto, a professora disse que a aluna não o tinha feito sozinha, pois não seria capaz de tamanho capricho. Então, deu nota 7. (FE64)

Nesse caso, a avaliação negativa que a professora tinha sobre a aluna impediu que ela considerasse o trabalho feito.
Já as(os) alunas(os) de pedagogia são mais sensíveis às macroinjustiças, e em seus relatos há menção de injustiça na escola devido à reprodução da desigualdade social, transformando-a em desigualdade escolar.

0 relato de uma aluna é representativo de tal sensibilidade à injustiça:

cursei o ensino médio em uma escola pública de uma pequena cidade do Paraná. Frequentei o primeiro ano no período noturno por trabalhar durante o dia, mas o ensino foi muito fraco. Deixei de trabalhar no segundo e no terceiro ano estudei no período diurno. Eu achava e acho injusto que os alunos que não podem deixar de trabalhar tenham um ensino de qualidade inferior. (FE39)

A violência física, a briga e o bullying também aparecem com mais força nos relatos dos alunos e professores da escola pública, em casos vinculados à quebra ou ao desrespeito de normas e regras. Essa é a base da injustiça e da violência. Um exemplo extremo disso está em um relato de uma estudante de pedagogia:

Uma menina (mais ou menos dez anos) com câncer no sistema nervoso central teve seu rosto esfregado na parede pelos colegas de classe. A diretora da escola justificou o acontecimento dizendo que a garota era lenta, passiva e não reagia às agressões dos colegas, portanto ela nada poderia fazer para ajudar a menina. A menina acabou se afastando da escola. (FE3)

\section{Quem sofreu a injustiça?}

Novamente nos interessamos em saber se é possível relatar casos pessoais de injustiça na escola.

Quadro 9 - Quem sofreu a injustiça?

\begin{tabular}{|c|c|c|}
\hline Com quem aconteceu? & Pedagogia & E.E.P.N.E. \\
\hline Comigo & $17 \%$ & $12 \%$ \\
\hline Com 0 outro próximo & $60 \%$ & $38 \%$ \\
\hline Com o outro genérico & $17 \%$ & $25 \%$ \\
\hline
\end{tabular}


Há mais possibilidades de falar sobre a injustiça sofrida concretamente na escola. Os discursos gerais (todos os professores sofrem, todos os alunos sofrem) ainda aparecem, mas há várias menções a casos pessoais ou ocorridos com pessoas próximas. Mesmo assim, ainda é difícil. Um exemplo dessa dificuldade é a expressão de uma aluna do EJA: "Graças a Deus, nunca passei por nenhuma situação (de injustiça)" (E55).

Algumas histórias, porém, podem ser contadas. Tal como a seguinte narrativa:

quando estava na sexta série do ensino fundamental, uma professora utilizou a minha descendência racial, em frente de todos os outros colegas da classe, para explicitar que eu estava sendo uma má aluna. 0 resultado foi raiva e desinteresse na matéria. (FE12)

Outro caso, na mesma direção, diz o seguinte:

eu estava na quinta série e meu professor de inglês disse para a sala toda que, no futuro, eu (era uma boa aluna) dirigiria um carrão enquanto que eles estariam andando a pé. Acho que dizendo isso ele fez uso da profecia auto-realizadora e negou a esperança no futuro a meus colegas de classe. (FE68)

Por sua vez, um aluno de EJA declara:

muitos professores não dão muita atenção no que os alunos perguntam, deixando o aluno constrangido no meio dos colegas. Isso para mim é muito injusto. (EJA31)

Trata-se de relatos plenos de dor. Em sua maior parte, eles referem-se a microinjustiças, injustiças cotidianas. Dizem de retribuições injustas, discriminação, quebra do princípio da igualdade, falta de diálogo.

Esse aspecto (e também os anteriores) pode ser relacionado com uma das questões que aparece principalmente nas respostas dos estudantes da escola pública: a falta de diálogo, a impossibilidade de dizer. É a escola o lugar do diálogo? Isso aparentemente não acontece. Se a justiça é o Outro, como nos diz Derrida, não está sendo possível ouvir esse Outro, vê-lo ou, quem sabe, suportá-lo.

Ainda lembrando Derrida (2007, p.33):

É injusto julgar alguém que não compreende seus direitos nem a língua em que a lei está escrita, ou o julgamento pronunciado. E, por mais leve e sutil que seja aqui a diferença de competência no domínio do idioma, a violência começa quando todos os parceiros de uma comunidade não compartilham totalmente o mesmo idioma. Daí pensar em "possibilidade de justiça".

A partir da análise da injustiça temos pistas para começar a perceber a possibilidade de justiça: onde estará?

\section{E a escola justa?}

Apresentamos, aos alunos e alunas, professoras e professores e gestores da E.E.P.N.E. a pergunta sobre o que seria uma escola justa. Mesmo considerando que a injustiça é o positivo, foi interessante observar o esforço para definir a escola justa. Obtivemos 71 respostas: respostas curtas, telegráficas. Em todas elas há, comumente, mais de um elemento de justiça.

Levando todos os relatos em consideração, foi possível estabelecer seis pontos principais que caracterizariam, inicialmente, a escola justa. Seriam eles:

- Que haja respeito à igualdade de direitos e recusa da desigualdade de tratamento. Se todos e todas são iguais perante leis, regras e combinados - sejam estes formalizados ou sociais, cotidianos -, o justo é que não existam dois pesos e duas medidas.

- Que haja respeito às diferenças e recusa da discriminação e do preconceito. 
- Em caso de violação de lei, norma, regra ou combinado, que exista uma punição (retribuição) justa e proporcional a determinada ação. Para tanto, obviamente, é preciso que existam regras (e acordos) conhecidas por todos.

- Que se reconheça o mérito.

- Que exista diálogo, comunicação, possibilidade de participação nas relações escolares.

- Que exista qualidade de ensino e princípios pedagógicos. Nesse sentido, a função da escola do ponto de vista da instrução, dos conteúdos e da formação é exposta como fundamental.

Haveria, assim, uma série de itens a definir o que é uma escola justa, sempre considerando a dificuldade em se delimitar - abstratamente - o justo. E podemos considerar que saímos da abstração quando compreendemos o cotidiano escolar como um lugar - difícil e conflituoso - de encontro.

Novamente com Derrida (2007, p.54-55), é possivel pensar que:

A justiça permanece porvir, ela tem porvir, ela é por-vir, ela abre a própria dimensão de acontecimentos irredutivelmente porvir. [...] Talvez seja por isso que a justiça, na medida em que ela não é somente um conceito jurídico ou político, abre ao porvir a transformação, a refundição ou a refundação do direito e da política.

"Talvez", é preciso sempre dizer talvez quanto à justiça. Há um porvir para a justiça, e só há justiça na medida em que seja possível o acontecimento que, como acontecimento, excede ao cálculo, às regras, aos programas, às antecipações, etc. A justiça, como experiência da alteridade absoluta, é inapresentável, mas é a chance do acontecimento e a condição da história.

Pode esse movimento estar contido em um programa, em um projeto, em uma política pública, em normas e regras de conduta?

Quando se chega ao momento em que há uma aproximação ao final de uma pesquisa, inúmeras novas perguntas se apresentam. Quais seriam os novos caminhos que responderiam ao menos parcialmente - às inquietações e angústias emergentes da verificação das percepções sobre justiça/injustiça em suas articulações com os direitos humanos e a violência? Como lidar, no cotidiano escolar, com o talvez da justiça, com as dissonâncias e os encontros entre os alunos e os professores que lá estão, com a forte demanda detectada de igualdade, respeito, reciprocidade, diálogo? É este o desafio: encarar o talvez, a possibilidade de uma escola justa. 


\section{Referências}

ARENDT, Hannah. Responsabilidade e julgamento. São Paulo: Companhia das Letras, 2004.

ASSMAR, Eveline Maria Leal. A experiência da injustiça na vida diária: uma análise preliminar de três grupos sociais. Psicologia: Reflexão e Crítica, Porto Alegre, v. 10, n. 2, p. 335-350, 1997. Disponivel em: <http://redalyc.uaemex.mx/pdf/188/18810211. pdf>. Acesso em: 12 dez. 2011.

BAUMAN, Zygmunt. 0 mal-estar da pós-modernidade. Rio de Janeiro: Zahar, 1998.

DERRIDA, Jacques. "La democracia es una promesa": Entrevista de Elena Fernandez con Jacques Derrida. Jornal de Letras, Artes e Ideias, p. 9-10, 12 oct. 1994. Disponível em: <http://www.jacquesderrida.com.ar/textos/democracia.htm>. Acesso em: 20 dez. 2012.

Força de Lei. São Paulo: Martins Fontes, 2007.

DUBET, François. 0 que é uma escola justa? Cadernos de Pesquisa, São Paulo, v. 34, n. 123, p. 539-555, set./dez. 2004.

0 que é uma escola justa: a escola das oportunidades. São Paulo: Cortez, 2008.

EWALD, François. Foucault, a norma e o direito. Lisboa: Vega, 1993.

FOUCAULT, Michel. 0 governo de si e dos outros. São Paulo: Martins Fontes, 2010.

FRASER, Nancy. Escalas de justiça. Barcelona: Herder Editorial, 2008.

HELLER, Agnes. Além da justiça. Rio de Janeiro: Ed. Civilização Brasileira, 1998.

IGLESIAS, Fábio; GÜNTHER, Hartmut. Normas, justiça, atribuição e poder: uma revisão e agenda de pesquisa sobre filas de espera. Estudos de Psicologia, Campinas, v. 12, n. 1, p. 3-11, 2007.

LARROSA, Jorge. Tecnologias do eu e educação. In: SILVA, Tomás Tadeu (Org.). 0 sujeito da educação: estudos foucaultianos. Petrópolis: Vozes, 2002. p. 35-86.

MARKO, Gabriela. 0 que é uma escola justa? Um estudo sobre a percepção de professores. Monografia (Iniciação Científica) Faculdade de Educação da Universidade de São Paulo, São Paulo, 2010.

MOORE JR., Barrington. Injustiça: as bases sociais da obediência e da revolta. São Paulo: Brasiliense, 1987.

RICOEUR, Paul. 0 justo. São Paulo: Martins Fontes, 2008.

SOUZA, Vivian Valentim de. Direitos humanos, justiça e violência: 0 debate acadêmico sobre 0 tema. Monografia (Iniciação Científica) - Faculdade de Educação da Universidade de São Paulo, São Paulo, 2010.

VENTURI, Gustavo (Org.). Direitos humanos: percepções da opinião pública: análises de pesquisa nacional. Brasília: Secretaria de Direitos Humanos da Presidência da República, 2010.

Recebido em: 22.06.2012

Aprovado em: 21.08.2012

Flávia Schilling é professora associada da Faculdade de Educação da Universidade de São Paulo e pesquisadora do Conselho Nacional de Desenvolvimento Científico e Tecnológico (CNPq). 